University of Windsor

Scholarship at UWindsor

\title{
Chinese Graduate Students and the Canadian Academic Library: A User Study at the University of Windsor
}

Guoying Liu

University of Windsor

Danielle Winn

Follow this and additional works at: https://scholar.uwindsor.ca/leddylibrarypub

Part of the Library and Information Science Commons

\section{Recommended Citation}

Liu, Guoying and Winn, Danielle. (2009). Chinese Graduate Students and the Canadian Academic Library: A User Study at the University of Windsor. Journal of Academic Librarianship, 35 (6), 565-573.

https://scholar.uwindsor.ca/leddylibrarypub/6

This Article is brought to you for free and open access by the Leddy Library at Scholarship at UWindsor. It has been accepted for inclusion in Leddy Library Publications by an authorized administrator of Scholarship at UWindsor. For more information, please contact scholarship@uwindsor.ca. 


\title{
Chinese Graduate Students and the Canadian Academic Library: a User Study at the University of Windsor
}

\author{
Authors: \\ Guoying Liu, Librarian, Leddy Library, University of Windsor \\ Email: gliu@uwindsor.ca \\ Guoying Liu is the corresponding author. \\ Danielle Winn, Information Literacy Librarian, Leddy Library, University of Windsor \\ Email: dwinn@uwindsor.ca
}

\begin{abstract}
This paper presents a pilot study that examined the information seeking behaviors of Chinese graduate students at the University of Windsor. Findings on current Chinese students' perceptions, expectations, and use of library services are highlighted including implications for academic libraries to meet international students’ information needs.
\end{abstract}

\section{Introduction}

The number of international students enrolling at Canadian universities and colleges has increased significantly over the past decade. In 1998, there were 85,803 foreign students studying in Canada, and by 2007 the total had risen to 176, 116. ${ }^{1}$ This represents an unprecedented increase of one hundred and five percent within ten years. During the same time period, the number of Chinese students that matriculated at Canadian postsecondary institutions increased from 3,505 to 41,082, representing an increase of one thousand seventy two percent. Ontario’s universities and colleges attract the majority of international students, with more than twenty percent choosing to study in Toronto and an additional seventeen percent studying elsewhere through out the province. ${ }^{2}$ Since the number of international students studying at Canadian universities is increasing steadily 
and rapidly, academic librarians need to assess how well their libraries are meeting the needs of this unique user group. The literature review in the following section reveals that there is an immediate need for research that examines the information needs of current international students in Canadian institutions.

The University of Windsor is located in Windsor, Ontario, Canada and serves 16,000 full and part time undergraduate and graduate students. ${ }^{3}$ The institution has the highest proportion of international students among Canadian universities, as 13 percent of its total population of students come from abroad. ${ }^{4}$ This is nearly double the national average of 7.4 percent. $^{5}$ In the 2008 Fall Semester, the University of Windsor had an enrolment of 1717 international undergraduate and graduate students, 432 (25\%) of whom were from mainland China. ${ }^{6}$ Chinese students currently make up the largest group of international students on the University of Windsor campus. The University of Windsor has two campus libraries: the Paul Martin Law Library which primarily serves law faculty and students and the Leddy Library that provides services to all other students and faculty members.

In the summer of 2008, the authors of this paper conducted a qualitative study to explore Chinese graduate students' perceptions and expectations of academic library services at University of Windsor Leddy Library. This study focused on the issues and challenges these students encountered in seeking information needed and the reasons and explanations for these issues. The findings have implications for Canadian academic libraries and other Western academic libraries to better serve this group of students. 


\section{Literature Review}

The literature exploring the information needs of international students and Western academic library services can be divided into two distinct periods: one is early research and includes articles published before 2000; the other is recent research and refers to materials published after 2000. Although research from different periods tends to have different focuses, all researchers identified the influence of language and cultural differences on the information use of international students, especially Asian students.

\section{Early Studies}

Most original studies before 2000 were completed in the mid-1990s or earlier. Many studies examined traditional library services to international students, such as library orientation $^{7}$ and bibliographic instruction ${ }^{8}$. Other studies addressed the problem from the perspective of international groups themselves by focusing on the information seeking behaviors of international students. It has been well documented that Asian students encounter various problems when using American academic libraries. While some of these challenges are due to limited proficiency with the English language, others are a result of their limited experience using libraries for the purpose of research. Badke ${ }^{9}$ identified the following as struggles for international students “...difficulty with the English language, unfamiliarity with our library systems, lack of comfort with technology, and tendency toward plagiarism.”

Language difficulties - According to Lewis ${ }^{10}$ when an Asian student reads text in English, their reading speed is commonly "less than half that of the average American student; oral comprehension of the Asian student is often slower in the same ratio.” 
Goudy and Moushey ${ }^{11}$ surveyed thirty-one university librarians and directors and found that the majority of participants believed that their library should offer separate instructional programs for international students. The reasons given included: "poor pronunciation and difficulty in oral communication and lack of adequate vocabulary” (p. 219). One solution offered by Liestman and $\mathrm{Wu}^{12}$ was to provide library instruction to students in their native language, because it's an efficient method of informing them of the library's services and teaching them how to use the library. Not surprisingly, the longer international students remain on English-speaking campuses the more their English language skills develop, and the more confident they feel when using the library for research purposes ${ }^{13}$. It is important to note that international students who speak English as a first language report fewer difficulties when using the library than students for whom English is an additional language ${ }^{14}$.

Cultural Challenges - Cultures can be classified as being either high-context or lowcontext $^{15}$. In high-context cultures such as China, it is the listener's responsibility to interpret the speaker's message even if the meaning was only implied. Countries such as Canada are low-context cultures, and the burden falls on the speaker to accurately communicate their message to the listener ${ }^{16}$. Another accepted method for comparing cultures is to determine whether they are individualistic or practice collectivism. In individualistic cultures, people value independence and the ability to focus on their own personal goals. Individuals from cultures that believe in collectivism engage in more interdependent relationships and feel that group goals should take precedence over individual goals ${ }^{17}$. Interestingly, cultures with low-context communication styles are 
generally individualistic while highly contextual cultures usually practice collectivism. Bilal $^{18}$ suggests that in order to successfully assist international students at the reference desk or during instructional sessions, librarians should "become aware of foreign students; backgrounds, cultural differences, and learning patterns.”

Limited Library Knowledge/Experience - Allen ${ }^{19}$ conducted quantitative research to investigate how international students interacted with American academic libraries. Her survey results indicated that there were a number of library features with which many students were unfamiliar, such as: online databases, interlibrary loans, and online catalogues. Other components of the library that were previously unknown to students included: “online catalogue workshops, term paper research counselling, large library collections, microfiche and microfilm, self service photocopying, and open stacks”. Bilal $^{20}$ found that: periodical, evaluation, index, bibliography, stacks, and classification were new terms to participants in her study. Bilal's study further revealed that Asian graduate students report that they did not need to use their institution's library for

research purposes while completing their undergraduate degrees. ${ }^{21}$ These findings lend strong support to the theory that using academic libraries is more challenging for international students because of their unfamiliarity with using such libraries for research purposes in their home countries.

\section{Recent studies}

Although less research has been conducted since 2000, there was an increase in the number of studies administered outside the United States. Furthermore, most original 
research in this period was done after 2004. During this time, library resources and services have changed dramatically due to the development of information technology. The Internet, electronic resources and innovative services became hot topics in the library world. Concurrently, the characteristics and previous library experiences of international students have experienced major changes. As stated in the introduction of this article, from 1998 to 2007, the number of international students attending school in Canada doubled, while the number of students from mainland China increased more than tenfold ${ }^{22}$. Current research needs to address these modern library features as well as revisit previously identified issues.

Language and cultural barriers - Hughes ${ }^{23}$ explored international students' online behavior at an Australian institution. The findings revealed that students had strong information technology skills but limited information literacy. Language limitations and cultural differences are still barriers for them to effectively use and evaluate online resources. Liao ${ }^{24}$ conducted a study comparing the information seeking behaviors of international and American graduate students. The results demonstrated that the effects of language, culture and technology barriers on international students' access to academic libraries have decreased. Ishimura's recent study revealed that Japanese students found the research process quite onerous, even though they believed they were skilled at "finding topics, searching, evaluating, organizing, and using information” ${ }^{25}$. He also found that after students finished the research component of an assignment, they needed additional assistance writing their papers. 
Library experience - A 2005 study by Jackson found that international students remain unaware of certain library services, including: interlibrary loan, individual assistance with a subject specialist, and chat reference ${ }^{26}$. Additional research in this area shows that even though the majority of international students have attained proficiency in computer literacy $^{27}$, they continue to experience challenges when attempting to locate information using databases such as LEXIS/NEXIS and OCLC First Search ${ }^{28}$. Song ${ }^{29}$ conducted research on the perceptions and expectations of international business students for electronic library services. The results revealed that most students did not think that virtual reference was very important to them. They also indicated that many students did not have access to electronic resources in their home countries. In a 2005 study, Song performed a comparative study of international business students and domestic business students. The results indicated that international students used the library primarily as a place to study, while domestic students viewed it as a place that provided resources for their research ${ }^{30}$.

Research indicates that in some cases, international students did not realize that there was a significant difference between their perceived and actual understanding of library related terms. A two part survey given to international students by Howze \& Moore led them to conclude that the students did not understand technology-based terminology that is commonly used in academic libraries ${ }^{31}$. Terms included: databases, citation, controlled vocabulary, circulation, and interlibrary loan. Amsberry noted that some common library terms are confusing to students because they have more than one meaning. This includes words such as: citation, abstract, and article ${ }^{32}$. 
Studies on Chinese students - For her master's thesis, Wang ${ }^{33}$ investigated academic library services to Chinese students in New Zealand. She combined qualitative interviews with quantitative analysis of secondary data from a user survey. Wang concluded that in order to successfully meet the information needs of Chinese students, libraries should promote their ability to offer an excellent environment for studying and their various services that are underused, including library instruction, reference services and individual appointments with subject librarians. Morrissey and Given conducted research that focused on library usage and information literacy skills among Chinese graduate students in Canada. They interviewed nine Chinese graduate students enrolled at the University of Alberta. The results indicated that the majority of students: relied heavily on Google to meet their research needs, did not evaluate the quality of their resources, did not comprehend the function of librarians, and retained more information from library instructional sessions that were organized by their professors than when they attended the traditional ones offered by the library ${ }^{34}$. However, most of the students were not recent graduates, and had graduated from Chinese institutions in the early 1990s or earlier. The majority "were returning to school after approximately ten years" 35 . Their previous library experience included the use of closed library stacks, and a card catalogue; but did not feature use of an online catalogue. Those experiences may reflect neither the current nature of academic libraries in mainland China nor the trend of current Chinese students' information needs.

The characteristics of recent Chinese students are not only different from students from other countries, but also different from students from China in the 1980s and 1990s. This includes: their levels of education, areas of study, English language preparation and 
exposure to Western culture prior to arriving in Canada. Even librarians familiar with previous Chinese students find it challenging to serve present-day Chinese students. More research is needed in order to answer the question- what are the information needs of current Chinese students? This study focused on Chinese graduate students who recently completed undergraduate or graduate degrees in mainland China.

\section{Methodology}

Given the exploratory nature of this study, qualitative method was adopted. In-depth qualitative interviews were conducted with twelve Chinese graduate students to collect the data between the months of May and August 2008. All of the individuals had received undergraduate or graduate degrees from an educational institution in mainland China, and were currently enrolled in a graduate program at the University of Windsor. This was their first time living in an English-speaking country. A variety of methods were used to recruit students for participation in this study and participants were intentionally selected from graduate programs according to the distribution of Chinese graduate students in the different faculties at the University of Windsor. The International Student Centre assisted by emailing bilingual (English and Chinese) recruiting letters to all Chinese students. Graduate secretaries from different departments, particularly the Faculty of Arts and Social Sciences, helped distribute the recruiting letters to students in their respective departments as well. Other methods used include: placing posters advertising the study in prominent locations in the International Student Centre, sending direct emails to students via the Dean's office, advertising on the Leddy Library News Blog and local Chinese online forums and through word of mouth. 
All interviews were conducted by the primary researcher in Chinese and recorded using a digital recorder. The researchers chose to carry out the interviews in Chinese because it is each participant's first language. This eliminated language barriers and encouraged participants to feel more relaxed and comfortable while responding to the questions. The interview questions featured a mix of open and closed-ended questions, and the interviews lasted between thirty-five and seventy minutes. The questions were divided into four sections. The first section focused on demographic data, and included questions about participants' current program and study level, length of time in Canada, and the institutions they attended while studying in China. The second section explored their library experiences while studying in China. Participants were asked about the following: their patterns of and reasons for library use, the layout of the library, organization of the books, availability of computers within the library, what they thought the role of librarians was, and whether or not they had ever sought assistance from a librarian. Section three asked students about their usage of Leddy Library, including their main purpose for using it and how it is both similar and different from their previous libraries. The final section was designed to assess how well participants understood library terminology and which library services and resources they were aware of. Participants were asked if they had heard of various terms, services, and resources, and were encouraged to share what they thought of them. All interviews were fully transcribed and coded using a grounded theory approach designed to identify common themes as they emerged from the data. 


\section{Results and Analysis}

\section{Participant Profile}

Twelve graduate Chinese students were interviewed; half of whom were male and half female. Approximately half of them started their studies in post-secondary institutions in China from 1996 - 2000, the remaining began after 2000. All participants received their undergraduate or graduate degrees in mainland China after 2000. Most of them came to Canada immediately after completing their studies in China. Nine participants have lived in Windsor between five and ten months, while the other three have lived there for two to three years. All students have studied at the University of Windsor for at least one semester.

Among the twelve students, eight were studying in master's programs, and the remaining four were $\mathrm{PhD}$ students. Eight students were registered in programs offered by the Faculties of Science and Engineering, two in Business, and one each in Education and Arts and Social Sciences.

\section{Language and Cultural Barriers}

Before arriving in Canada, all students completed the Test of English as a Foreign Language or the International English Language Testing System (TOEFL/IELTS) exams and achieved scores that met the University’s requirements. Nine of them began learning English in grade 5, and the other three did not begin studying it until they entered junior high school (grade 7). All participants studied English for more than ten years in China before starting their studies abroad. 
Few students felt they had problems with every element of the English languagereading, speaking, listening and writing. However, nine out of the twelve participants admitted that they had difficulties with some aspects of English. Speaking was the biggest challenge for them, listening was second and was followed by writing. These responses indicated that most students have problems expressing themselves in English. Fortunately, one of this project's researchers is a native Chinese speaker, and all interviews were conducted in Chinese in this study.

Participants were also asked if they had experienced or recognized any difficulties with their studies that were caused by cultural differences. Almost all participants answered no. The only student that acknowledged that cultural differences do exist is the one who had been in Canada for the longest time. He stated that he recognized some cultural differences when he tried to find a co-op job. The student was enrolled in an MBA program, and had already earned a masters degree in physics at the University of Windsor.

"The way people think is different from which in China. For example, when I looked for a job, the employers in China would first look at my transcripts and the university I graduated. It is different in Canada. It seems that the employers here don’t care much about my grades. They evaluate a candidate just through asking questions and talking with them."

He thought that Chinese students were more modest, quieter, and may appear to lack confidence when compared to other students. Modesty is considered to be a great virtue in Chinese culture. 
"It is not good for my job-hunting. Chinese students need to be more confident in speaking in public.”

In addition, researchers found that many students tended to solve problems by themselves rather than asking for help. For example, two students complained that they had trouble logging into the Inter-Library Loan (ILL) online page on the library website. One tried a couple of times and had never been able to complete the process. The other participant did not understand what username or password he should use. In the end, both of them gave up and were never successful using the service. When asked if they had requested assistance from friends, librarians or library staff, they all answered no and the reason was always “I don't want to bother others”. Although this finding may seem to contradict what one would expect from individuals raised in a collective culture, they do not because group goals are more important than individual goals. As a result, in a relation-oriented culture like China's, people tend to avoid disturbing others in order to maintain a harmonious and courteous relationship, which is a major group goal.

Cultural differences are still a barrier to Chinese students fully taking advantage of existing library resources whether they are aware of them or not.

\section{Experiences with and Perceptions of Libraries in China}

All participants spent at least four years attending postsecondary institutions in China. Some of them spent six years or longer studying to complete their undergraduate or graduate degrees. They all had experience using academic libraries in China.

Most students went to a library regularly, usually a couple of times per week. This was particularly true during their fourth year of undergraduate or graduate studies. 
However four participants recalled that they did not go to the library often, but heavily relied on its online resources, including the online public access catalogue and electronic books and databases.

While at university in China, participants' primarily used the library to study, borrow books, or access electronic resources. Most students stated that the layout and organization of books was similar to Leddy Library. Two of them said that they had new library buildings that stored current materials, while older resources were stored in the old buildings. All libraries offered computer access though it was rarely free.

"I went to there often to use the computer because it was the only wired place on campus”. One student recalled.

In China, students borrowed books to complete their academic assignments, but also to fulfill their desire to read for pleasure, with such books as novels and biographies. They frequently had difficulty locating books to read leisurely at Leddy Library.

“This summer, I want to read some English novels. But I do not know how to search them in the library catalogue. In my area, I know well where the materials are and how to find them.” One student complained.

Some students stated that libraries in China had larger and more diverse print and electronic collections than Leddy Library. However, other students indicated that Leddy Library had more resources. Students also stated that many online resources were unavailable to undergraduate students in China.

With regard to the library catalogue, two students still used a card catalogue. Other two participants experienced the transition from card catalogue to the online public access catalogue during their studies in China. Most participants who had experience 
with online catalogue found the interface and organization of Chinese online catalogues to be similar to Leddy Library's. The main difference was in language, as Chinese catalogues used Chinese and Leddy's used English. Two students also mentioned a service similar to the inter-library loan system available to students throughout Ontario. Through these services, students could borrow books or request articles from other libraries. However, it was quite slow and students reported that it could "take one month to get an article”. Additionally; it was not free to students or faculty members.

"My supervisor paid the fee for me”. A student who had completed her master's degree in China commented.

Participants were asked about their experiences with reference help. A typical answer was- "no such thing in China". When asked what they thought were the primary professional responsibilities for Chinese librarians, almost all of them said maintaining books and checking them in and out. Most students seldom or rarely sought assistance from a librarian, and if they did it was mainly for help locating a book.

“At each floor of the library, there was a librarian helping student locate books. They were very friendly". This student praised the Chinese "librarian" that assisted her.

Only one student who was a PhD candidate at a Chinese institution thought that "librarians were knowledgeable and helpful to my research." She also mentioned a service where librarians provided assistance with evaluating the originality of research project proposals. However, this service was only available to $\mathrm{PhD}$ students and faculty members. 
While studying in China, three participants took courses on information retrieval or database searching. These courses were taught by librarians and generally offered to undergraduate students as an optional course. Classes focused on how to locate resources using databases but did not cover how to evaluate information or how to use it ethically. Two of the students thought it was useless because it was "offered to undergraduate students. At that time, students did not need to do research, and did not have much access to databases either." Only one participant found the course rewarding and shared that he became search savvy as a direct result of taking the course.

Previous studies have identified limited library experience and lack of technology skills as posing major challenges to international students when using American academic libraries. However, there was not any evidence of the existence of these problems among our sample of students. Apparently, academic libraries in China now offer more resources and services that are similar to those found in Western academic libraries. The main problems that this student sample had with a modern academic library were not understanding the role of librarians and being unfamiliar with innovative services and library terminology.

\section{Library Use at Leddy Library}

Students reported that they do not go to Leddy Library as often as they went to their academic library when studying in China. One of the reasons is that some students have their own private places to study.

“I have my own lab. I only come to library for borrowing books”, said a Master’s student in Earth Science. 
Some students stated that the physical environment at Leddy Library is not conducive to studying for the following reasons:

"It is noisy. In some areas, it is not clean. Usually my friends and I go to Law Library for study".

"It is crowded. There is not enough study room."

One student had concerns about the safety of his personal belongings.

"I used to come to Leddy Library often, but not any more since last semester. One of my classmates lost his wallet when he was studying here. My roommate's laptop went missing in the library as well... now I study in the classrooms or in my living place.”

These observations are consistent with comments received on the "Library as Place" section of the 2007 LibQUAL+ survey that was completed by students and faculty at the University of Windsor ${ }^{36}$.

Almost all participants relied heavily on Leddy's electronic resources, including both databases and e-books. Some stated that their professors had informed them about the key databases and library subject guides available in their areas of study. Others indicated that they had been familiar with certain databases before they came to Canada. Most of them were unaware of the research and writing guides available on the library website. The close relationships that graduate students had with their professors led them to understand, use and value the library services their professors told them about. However, they demonstrated a lack of knowledge about other important library services.

All students were very confident with their ability to locate books in the library. 
“After a couple of visits, I got familiar with the library. I know where I can find books in my area.”

Most students did not have problems searching for books using the library catalogue. However, two participants complained that they could not locate the link to check their accounts online, which they often did in China. When the researcher showed them the login button they realized that they did not understand the term "patron" which was the word used for the hyperlink that allowed them to login and view their accounts. The section titled "Understanding of Library Terminology" will provide additional examples of students’ unfamiliarity with library jargon.

\section{Awareness of Library Services}

During the interviews, students were asked if they had heard of a variety of different library services. If they answered yes, follow-up questions were asked to ascertain whether or not they had used the services and how they felt about them.

The first group of services includes: library tours, orientations and instruction sessions. Over one-third of the students had never heard of any of these services.

“I haven’t heard about those kinds of session. My supervisor and professors have never mentioned that.”

Less than one-third of the students had participated in these types of library outreach. Among those who had attended a tour, orientation, or instruction session, almost all of them found the sessions helpful, and no one thought they were a waste of time. 
Other students had heard of these sessions, but had never attended them. One student said:

"I came here late because I had a problem with my visa. So I missed all orientation events.”

Two of them did not think the sessions would be useful.

“I don’t think these sessions are helpful because I can get online resource I need from the library on my own...I don’t want to waste my time.”

The findings indicate that Leddy Library may need to better promote its services to this particular group of students.

The following list of resources and services offered by Leddy Library was provided to each participant to determine their familiarity with and feelings about them:

Archives

CRC (Curriculum Resource Centre)

Data Centre

Headphone lending

Media Centre

RACER (interlibrary loan)

The results revealed that participants are unaware of many library services and resources. Over half of the participants did not know that any of these services or resources was available at the library. Although some services may not be relevant to all students (the Archives, CRC); services such as interlibrary loan and the Data Centre are potentially useful to most of them. Only two out of the twelve students had heard of the 
Data Centre. Many students were excited to learn that these services existed and replied yes when asked if they would use them in the future.

Leddy Library's reference services were listed on a separate sheet, and participants were given a copy during the interview. The following reference services were included on the sheet:

Reference Desk

Chat-with-a-Librarian

One-on-One Research Assistance

Most students knew about the reference desk and thought it was extremely helpful. This may be because the reference desk is highly visible to students, as it can be seen shortly after entering the library. Ten out of the twelve had never heard about the other types of reference services, and only then because they had been directly informed by their professors or friends. Most students were interested in receiving one-on-one research assistance and felt they may try it in the future.

\section{Understanding of Library Terminology}

A list of library terminology was provided to all participants as follows:

Call number

Check in/check out

Recall

Renewal

Reserved materials

Holdings 


\section{Information literacy}

Reference resources

Encyclopedia

Directories

Students had a strong understanding of basic library terminology, such as: call number, check in, check out and renewal. However, comprehension of jargon such as “recall” was much lower, and many participants were unaware of the recall service. During the interview, one student complained that the loan period at Leddy Library is too long because graduate students may borrow books for an entire semester.

“In China it’s only 3 weeks. I can wait for 3 weeks for the books to be returned, but how can I wait for a semester?”

Eleven out of the twelve students did not know what the terms "holdings" and “information literacy” meant. More than half of the students did not understand the words “reference resources”, “encyclopedia”, or “directories”. When asked, most of them agreed that a pamphlet featuring a glossary of these terms in English with Chinese translations would be helpful.

\section{Issues of information use}

This study also uncovered some issues regarding information use among Chinese graduate students. Some participants were unaware of the legal and ethical issues surrounding information access and use. For example, two students admitted that they shared resources with friends at other institutions in China or in the United States. This finding is consistent with the results of the study by Morrissey and Given ${ }^{37}$. Furthermore, 
many students were unaware of the importance of citing information correctly, although they were fully aware of the concept of plagiarism. One of the authors recently received a question from a student interviewed in the summer of 2008. During the interview, he said “I don’t think I will have any problem with citing information for my paper”. An important paper he recently submitted was returned by the professor, who requested that he re-do the bibliography. He recalled the interview question and asked for help. It turns out that he did not comprehend citation styles or their related formats at all.

\section{Discussions and Conclusions}

Language and cultural differences are still barriers to current Chinese students using North American academic libraries. Students tend not to seek assistance when encounter problems using library services. Many of them have difficulties in expressing themselves effectively in English. Although they have a strong understanding of basic library terms, such as call number, check in, check out and renewal, Chinese students are not familiar with many other terms, including patron, recall, holdings, etc. As a result, they are not able to take full advantage of the resources and services the library has to offer. It is suggested by these students that a pamphlet featuring a glossary of these terms in English with Chinese translations would be helpful.

The results indicate that academic libraries in China now offer more resources and services that are similar to those found in Canadian academic libraries. Open stacks and online resources are not new to Chinese students any more. Students also reported that the layout and organization of materials are similar to those at Leddy Library. Some libraries even offer the inter-library loan service though it does not appear to be as 
popular and is slow and costly. Chinese academic libraries also provide computer access to students. Although some students used a card catalogue while studying in China and some others experienced the transition from card catalogue to online catalogue, most students were familiar with online catalogue and electronic resources. These provide evidence of the technological development of academic libraries in China in recent years. Computer and related library resources are not a problem to most Chinese students any more.

Although some Chinese academic libraries provided information retrieval courses to students, students did not understand the professional role of librarians, nor were they aware of the general and specialized research assistance that librarians are able to provide. This supports the finding that reference services in China are much more limited and do not exist in as many different formats (desk, phone, chat, and email reference). Furthermore, students are unaware of many general library areas or services, including Academic Data Centre, Media Centre or inter-library loan. Students were also unaware of the existence of various innovative library services, such as the Academic Data Center and the option of making appointments to meet with subject specialists. As a result many services are underused by this user group. Results also demonstrate that the majority of students do not have a strong understanding of the legal and ethical issues involving information use. Many students were unaware of what citation style they should use for their assignments and others expressed that they did not feel that following a particular style was important.

On the other hand, students are confident with their information searching skills. They are not aware of their incognizance of many library resources available in North 
American academic libraries as well as issues associated with information use. These all bring new challenges for academic librarians to effectively educate this group. It would be useful for librarians to work with professors and staff in the graduate schools to promote library services to Chinese students because of the close relationship of them with their departments.

This study lends itself to numerous areas for future research. A quantitative study would help generalize the findings by this qualitative study. Investigation on the information seeking behaviours of Chinese undergraduate students and comparison to graduate students would provide better understanding on Chinese student group for librarians. Since the University of Windsor is the most diverse campus in Canada, there are ample opportunities to investigate the challenges that international students from countries other than China experience when using Leddy Library. Studies conducted in different institutions across Ontario and Canada would also provide insightful understanding of the impacts of different geographic, academic and community environments on the information needs of international students.

\section{Acknowledgement}

Research described in the paper was supported by the University of Windsor Research Grant.

\section{Notes and References}

1. Citizenship and Immigration Canada, "Facts and figures 2007- Immigration overview: permanent and temporary residents, Canada- December $1^{\text {st }}$ stock of foreign 
students

by

top

source

countries”

http://www.cic.gc.ca/english/resources/statistics/facts2007/temporary/18.asp.

2. Ibid.

3. University of Windsor, “About the University” http://www.uwindsor.ca/about.

4. Sarah Sacheli, "Foreign students flock to U of W," The Windsor Star 9 (January 2004): 1 (sec. A3).

5. Statistics Canada. "University enrolment," http://www.statcan.gc.ca/dailyquotidien/061107/dq061107a-eng.htm.

6. Office of Institutional Analysis- University of Windsor.

7. Daniel Liestman \& Connie Wu, "Library Orientation for International Students in Their Native Language,” Research Strategies 8 (4) (1990): 191-196;

Yan Liao, Mary Finn, \& Jun Lu, "Information-Seeking Behavior of International Graduate Students vs. American Graduate Students: A User Study at Virginia Tech 2005,” College \& Research Libraries 68 (1) (2007): 5-25;

Vivian Howard, “Orientation programs for international students at Canadian academic libraries” (master’s thesis, Dalhousie University 1995), 1-243.

8. Frank Wm. Goudy \& Eugene Moushey, "Library Instruction and Foreign Students: A Survey of Opinions and Practices Among Selected Libraries," The Reference Librarian 10 (1984): 215-226;

Dania M. Bilal, “International Students’ Acquisition of Library Research Skills: Relationship with Their English Language Proficiency,” The Reference Librarian 24 (1989): 129-145. 
9. William Badke, "International Students: Information Literacy or Academic Literacy?” Academic Exchange 6 (4) (2002): 60-65.

10. Mary Genevieve Lewis, "Library Orientation for Asian College Students," College \& Research Libraries, 30 (1969): 267-272.

11. Frank Wm. Goudy \& Eugene Moushey, "Library Instruction and Foreign Students: A Survey of Opinions and Practices Among Selected Libraries," The Reference Librarian 10 (1984): 129-145.

12. Daniel Liestman \& Connie Wu, "Library Orientation for International Students in Their Native Language,” Research Strategies 8 (4) (1990): 191-196.

13. Mary Beth Allen, "International Students in Academic Libraries: A User Survey," College \& Research Libraries 54 (4) (1993): 323-333.

14. Yan Liao, Mary Finn, \& Jun Lu, "Information-Seeking Behavior of International Graduate Students vs. American Graduate Students: A User Study at Virginia Tech 2005,” College \& Research Libraries 68 (1) (2007): 5-25.

15. Edward T. Hall, “Beyond culture $1^{\text {st }}$ ed.” (Garden City, NY: Anchor, 1976).

16. Li Zhang, "Communication in academic libraries: an East Asian perspective," Reference Services Review 34 (1) (2006): 164-176.

17. Sang-Pil Han \& Sharon Shavitt, "Persuasion and Culture: Advertising Appeals in Individualistic and Collectivistic Societies," Journal of Experimental Social Psychology 30 (1994): 326-350.

18. Dania Bilal, “International Students' Acquisition of Library Research Skills: Relationship with Their English Language Proficiency,” The Reference Librarian 24 (1989): 129-145. 
19. Mary Beth Allen, “International Students in Academic Libraries: A User Survey,” College \& Research Libraries 54 (4) (1993): 323-333.

20. Dania Bilal, “International Students’ Acquisition of Library Research Skills: Relationship with Their English Language Proficiency,” The Reference Librarian 24 (1989): 129-145.

21. Ibid., 136.

22. Citizenship and Immigration Canada, "Facts and figures 2007- Immigration overview: permanent and temporary residents, Canada- December $1^{\text {st }}$ stock of foreign students by top source countries” http://www.cic.gc.ca/english/resources/statistics/facts2007/temporary/12.asp

23. Hilary Hughes, “Actions and Reactions: Exploring International Students' Use of Online Information Resources,” Australian Academic and Research Libraries 36 (4) (2005): 169-179.

24. Yan Liao, Mary Finn, \& Jun Lu, "Information-Seeking Behavior of International Graduate Students vs. American Graduate Students: A User Study at Virginia Tech 2005,” College \& Research Libraries 68 (1) (2007): 5-25.

25. Yusuke Ishimura, "Information literacy in academic libraries: Assessment of Japanese students' needs for successful assignment completion in two Halifax cities,” (master’s thesis, Dalhousie University,2007), 1-99.

26. Pamela A Jackson, "Incoming international students and the library: a survey," Reference Services Review 33 (2) (2005): 197-209.

27. Ibid., 202. 
28. Diane DiMartino \& Lucinda Zoe L, "International students and the library: New users and new instruction," in Teaching the new library to today's users, edited by Trudi E. Jacobson \& Helene C.Williams (New York: Neal-Schuman, 2000), pp. 17-43.

29. Yoo-Seong Song, "International business students: A study on their use of electronic library services,” Reference Services Review 32 (4) (2004): 367-373.

30. Yoo-Seong Song, “A comparative study on information seeking behaiors of domestic and international business students,” Research Strategies 20 (2005): 23-34.

31. Philip C. Howze \& Dorothy M. Moore, "Measuring international students' understanding of concepts related to the use of library-based technology,” Research Strategies 19 (2003): 57-74.

32. Dawn Amsberry, "Talking the Talk: Library Classroom Communication and International Students,” The Journal of Academic Librarianship 34 (4) (2008): 354357.

33. Belle Xinfeng Wang, “Academic library services to Chinese international students in New Zealand,” (master’s thesis, Victoria University of Wellington,2006), 1-124.

34. Renee Morrissey \& Lisa M. Given, "International Students and the Academic Library: A Case Study", Canadian Journal of Information and Library Science 30 (3/4) (2006): 221-239.

35. Ibid.,. 227.

36. "University of Windsor: Leddy Library Annual Report,” (working paper, Leddy Library, University of Windsor, 2007/2008). 
37. Renee Morrissey \& Lisa M. Given, "International Students and the Academic Library: A Case Study", Canadian Journal of Information and Library Science 30 (3/4) (2006): 221-239. 